Solid Earth Discuss., doi:10.5194/se-2016-42, 2016

Manuscript under review for journal Solid Earth

Published: 8 March 2016

(c) Author(s) 2016. CC-BY 3.0 License.

\title{
Visualization and Quantification of the Penetration Behavior of Bentonite Suspensions into the Pore Network of non-cohesive Media by using $\mu$-CT Imaging
}

\author{
Britta Schoesser $^{(1)}$, Atefeh Ghorbanpour ${ }^{(2,1)}$, Matthias Halisch ${ }^{(3)}$, Markus Thewes $^{(1)}$ \\ (1) Institute for Tunnelling, Pipeline Construction and Construction Management, Ruhr- \\ Universität Bochum, Universitätsstraße 150, D-44780 Bochum \\ (2) LV Baumanagement AG, Banksstraße 4, D-20097 Hamburg \\ (3) Leibniz Institute for Applied Geophysics (LIAG), Dept. 5 - Petrophysics \& Borehole \\ Geophysics, Stilleweg 2, D-30655 Hannover
}

\begin{abstract}
Bentonite suspensions are an essential tool for different construction techniques in horizontal and vertical drilling, in diaphragm and bored pile walls as well as in pipe jacking and tunneling. One of the main tasks of the suspension is to prevent the surrounding ground from collapsing during the excavation process of trenches, drill holes or tunnels. In order to maintain the soil stability close to the excavation, the bentonite suspension has to counteract against the earth and water pressure. Therefore, the pressure acting in the suspension has to counter the groundwater pressure and to be transferred into an effective stress to support the soil skeleton.
\end{abstract}

The creation of a pressure transfer mechanism can be achieved in two ways. A direct relation exists between the mechanism of the pressure transfer and the penetration behavior of the bentonite suspension in the subsoil. The relation of the size of the bentonite particles in the suspension and the size of the pores in soft soil is decisive. In addition, the yield strength of the bentonite suspension is a determining factor.

Concerning the penetration behavior two theoretical models exist actually: formation of a filter cake and entire penetration into the pore space. If the pore space is smaller than the size of the bentonite particles, a filtration process takes place. Here, the bentonite particles agglomerate gradually at the entrance of the pore space and create a thin nearly impermeable layer. This membrane is named filter cake. If the pore space is larger than the size of the bentonite particles, the suspension penetrates into the subsoil up to a certain depth.

These models have a more theoretical character due to missing visual evidence concerning the interaction of the bentonite suspension in the pore space. Here, the micro CT technique delivers a valuable contribution to this research.

Keywords: $\mu-C T$, non-cohesive porous media, bentonite suspensions, non-Newtonian fluid, penetration depth, filter cake 
Solid Earth Discuss., doi:10.5194/se-2016-42, 2016

Manuscript under review for journal Solid Earth

Published: 8 March 2016

(c) Author(s) 2016. CC-BY 3.0 License.

Bentonite suspensions are an essential tool for different construction techniques in horizontal and vertical drilling, in diaphragm and bored pile walls as well as in pipe jacking and tunneling. One of the main tasks of the suspension is to prevent the surrounding ground from collapsing during the excavation process of trenches, drill holes or tunnels. In order to maintain the soil stability close to the excavation, the bentonite suspension has to counteract against the earth and water pressure. Therefore, the pressure acting in the suspension has to counteract the groundwater pressure and has to be transferred into effective stress to support the soil skeleton.

Currently, the dominant theory in tunneling practice is adopted from diaphragm wall technology [Müller-Kirchenbauer, 1977] and summarized in DIN 4126 (2004). According to German Standard [DIN 4126, 2004] the formation of a pressure transfer mechanism in terms of effective stress can be achieved in two ways: (a) with a thin and flexible membrane or (b) with a limited penetration zone in the soil.

The membrane, named filter cake (a), develops when the pore size of the soil is smaller than the size of the suspended bentonite particles [Walz, 2001]. Here, the bentonite particles are filtered at the entrance of the pore space and the remaining filtrate water drains through the soil. By gradual agglomeration of more bentonite particles, a thin, impermeable membrane is build (Figure 1 (left)). Here, the suspension pressure is transferred through the membrane area in terms of effective stress to the soil skeleton.

In case the pore size of the soil exceeds the size of the suspended bentonite particles, the suspension penetrates completely into the pore space of the ground up to a certain depth [Walz, 2001]. Due to the yield point of the bentonite suspension, shear stresses are transferred along the surface of the soil particles within the penetration zone (b). The penetration process stagnates in a certain depth, when the suspension pressure, transfer of shear stress and groundwater pressure are balanced (Figure 2 (left)).

[Mueller-Kirchenbauer 1977] describes the direct relation between the mechanism of the pressure transfer and the penetration behavior of the bentonite suspension in the subsoil in reference to the pore size in detail.

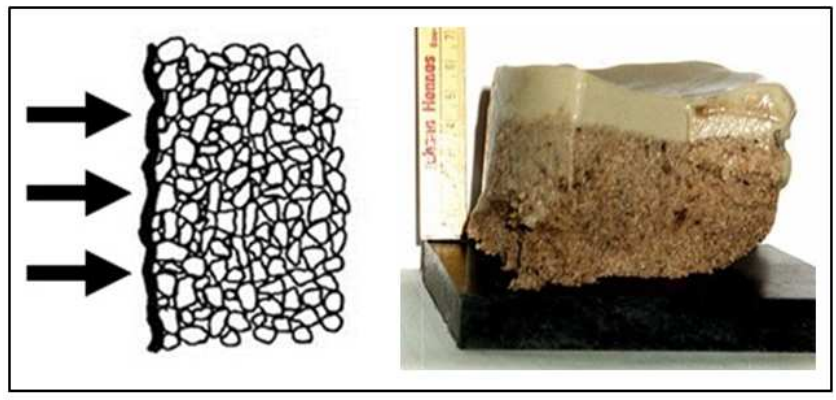

Figure 1: Theoretical principle of support pressure transfer in the soil due to formation of a filter cake [Zizka \& Thewes, 2015] (left) and experimental result of filter cake on macroscale [Imerys, 1998] (right). 
Solid Earth Discuss., doi:10.5194/se-2016-42, 2016

Manuscript under review for journal Solid Earth

Published: 8 March 2016

(c) Author(s) 2016. CC-BY 3.0 License.

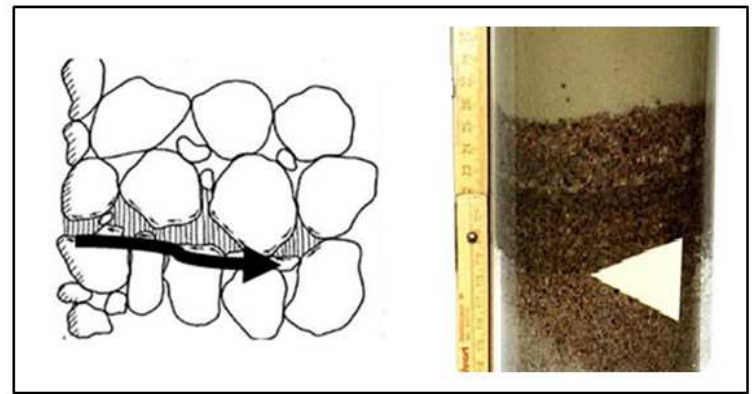

Figure 2: Theoretical principle of support pressure transfer in the soil due to formation of a penetration zone [Zizka \& Thewes, 2016] (left) and experimental result of a penetration zone on macroscale [Imerys, 1998] (right).

Based on long-term practical experience, the theoretical principles are widely accepted [Anagnostou \& Kovári 1994, Krause 1987, Boere 2001, Bezuijen 2001, Zizka \& Thewes 2015] and in addition proven by several experimental expertise on the macroscale [IBECO, Min et.at. 2013, Heinz 2006, Arwanitaki 2009] (Figure 1 (right), Figure 2 (right)).

In this study the penetration process is visualized and analyzed on the microscale using $\mu$ CT for the first time. The analysis provides detailed information concerning the interaction between the bentonite suspension and the non-cohesive media within the pore space. Furthermore, the $\mu$-CT imaging provides the determination of parameters e.g. porosity, pore size, pore size distribution and particle size distribution. By analyzing the contact angle between the fluid and the glass beads, the bentonite suspension is identified as a "wetting fluid" with a contact angle $<90^{\circ}$. Both principles - filter cake and penetration - are identified and analyzed using $\mu$-CT imaging so that these phenomena are validated on the microscale.

As an important result, the single phenomena of the filtration process of the bentonite suspension can be demonstrated in detail. Beside the "standard" identification of solid particles (glass beads), air and the penetrated bentonite suspension, the filtered bentonite particles in the filter cake and the filtrated suspension water are detected.

\section{Materials \& Methods}

\subsection{Materials}

Bentonite is a natural clay. Main component of bentonite is the plate like clay mineral Montmorillonite. A single Montmorillonite crystal consists of 15-20 elementary layers. Between these elementary layers different cations (e.g. $\mathrm{Na}^{+}, \mathrm{Ca}^{2+}, \mathrm{Mg}^{2+}$ ) are adsorbed. In case of $\mathrm{Na}^{+}$ions the bentonite is called Sodium bentonite, in case of $\mathrm{Ca}^{2+}$ ions it is a Calcium bentonite.

Preparation of a bentonite suspension consists of three steps: The powdery bentonite is suspended in water (1) and dispersed by introducing high shear forces (2). The shear forces separate the single crystal layer mechanically and distribute them homogeneously in the suspension. Due to an additional swelling process (3), water molecules are embedded between the elementary layers of the Montmorillonite crystal. These water molecules are adsorbed at the cations and at the surface of the single layers as well. Hence, the distance 
Solid Earth Discuss., doi:10.5194/se-2016-42, 2016

Manuscript under review for journal Solid Earth

Published: 8 March 2016

(c) Author(s) 2016. CC-BY 3.0 License.

between the layers increases and the volume of the dispersed/suspended solids changes. This break-up of the layer corpuses is essential for the rheological properties of the bentonite suspension to develop. The required swelling time of different bentonites varies between 4 16 hours. Afterwards the particle size of the suspended $\mathrm{Na}$ - and $\mathrm{Ca}$-bentonite particles can be determined (Appendix 1). In the experimental study bentonite suspension with varying solid contents were employed: Ca-bentonite in $25 \%$ by weight, Na-bentonite in $8 \%$ and 13 $\%$ by weight.

Glass beads with particle size of $2 \mathrm{~mm}$ and $600 \mu \mathrm{m}$ and a mean density of $2600 \mathrm{~kg} / \mathrm{m}^{3}$ were used to ensure the reproducibility of the performed combinations of bentonite suspensions and non-cohesive media. The surface structure of the glass beads was determined using SEM (Figure 3). Here, small parts of unevenness were detected.
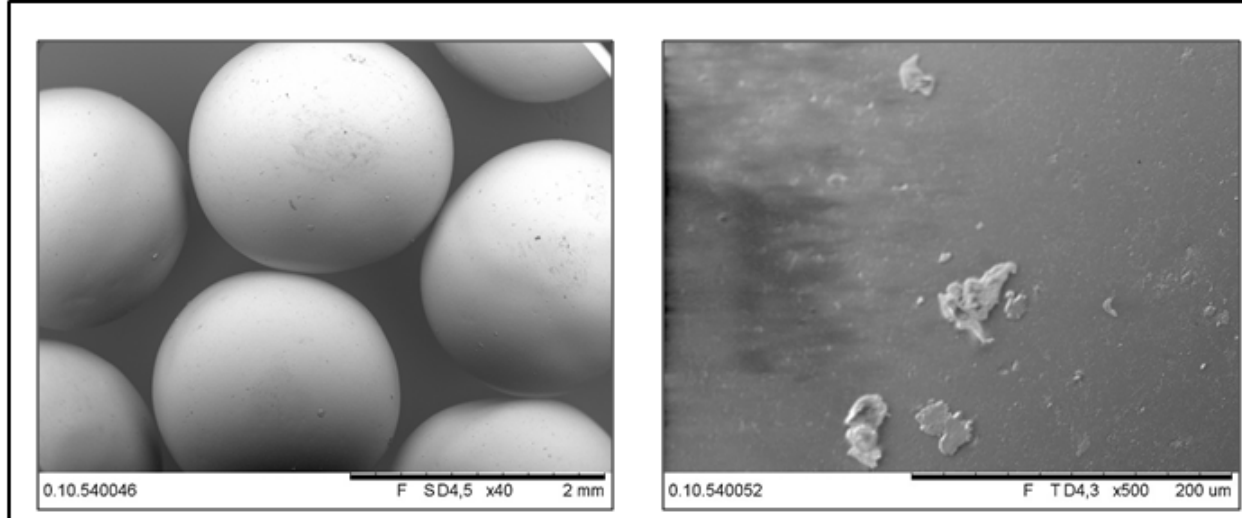

Figure 3: Image of the surface condition of the $2 \mathrm{~mm}$ glass beads using Scanning Electron Microscopy (SEM)

The penetration tests were conducted in test tubes made of acrylic glass $(\varnothing 37 \mathrm{~mm}$ and length $160 \mathrm{~mm})$ and silica glass $(\varnothing 21 \mathrm{~mm}$ and length $200 \mathrm{~mm}$ ) in order to provide the most suitable material for the $\mu$-CT scans. The label of each sample describes the container type, the type and concentration of bentonite suspension and the size of the glass beads. Table 1 shows the combinations for scanning with $\mu-\mathrm{CT}$, which provide the performance of a filter cake or the penetration process.

Table 1: Combinations of test tube material, bentonite suspensions and glass beads size for CT scans

\begin{tabular}{|l|c|c|c|}
\cline { 2 - 4 } & $\begin{array}{c}\text { Material of } \\
\text { test tube }\end{array}$ & $\begin{array}{c}\text { Bentonite type }+ \\
\text { solid content }\end{array}$ & $\begin{array}{c}\text { Size of glass } \\
\text { beads }\end{array}$ \\
\hline Sample 1 & silica glass & Calcium 25\% & $2 \mathrm{~mm}$ \\
\hline Sample 2 & silica glass & Calcium 25\% & $600 \mu \mathrm{m}$ \\
\hline Sample 3 & silica glass & Calcium 25\% & $2 \mathrm{~mm}+600 \mu \mathrm{m}$ \\
\hline Sample 4 & silica glass & Sodium $8 \%$ & $600 \mu \mathrm{m}$ \\
\hline Sample 5 & acrylic glass & Calcium 25\% & $2 \mathrm{~mm}$ \\
\hline Sample 6 & silica glass & Sodium 13\% & $2 \mathrm{~mm}+600 \mu \mathrm{m}$ \\
\hline
\end{tabular}


Solid Earth Discuss., doi:10.5194/se-2016-42, 2016

Manuscript under review for journal Solid Earth

Published: 8 March 2016

(c) Author(s) 2016. CC-BY 3.0 License.

\subsection{Preliminary laboratory experiments}

In preparation of the $\mu$-CT scans, fundamental tests were performed in the bentonite laboratory at Ruhr-University Bochum to identify and determine the influence of different parameters on the penetration behavior of the bentonite suspensions into glass beads. Furthermore, the penetration depth of the suspension has to be limited to some extend in order to ensure a high quality of the $\mu$-CT scans due to smaller areas of interest. This is a challenging task because bentonite suspensions are non-Newtonian fluids with a yield point and exhibit thixotropic behavior [Luckham \& Rossi 1999, Maxey 2007, API RP 13B]

Here, the bentonite suspensions were prepared with varying solid contents of $\mathrm{Ca}^{2+}$ in $20 \%$ and $25 \%$ by weight and $\mathrm{Na}^{+}$in $8 \%$ and $13 \%$ by weight. All suspensions are combined with the glass beads of $2 \mathrm{~mm}, 600 \mu \mathrm{m}$ and a combination of $2 \mathrm{~mm}+600 \mu \mathrm{m}$. After swelling times of $24,48,72,96,120$ and 192 hours the penetration tests were performed using test tubes of acrylic glass and silica glass and the penetration depth was measured.

The suspension made of $\mathrm{Ca} 25 \%$ penetrates into the glass beads size of $2 \mathrm{~mm}, 600 \mu \mathrm{m}$ and the combination $2 \mathrm{~mm}+600 \mu \mathrm{m}$. The highest penetration depth is reached in the coarse material of $2 \mathrm{~mm}$; the penetration depths in $600 \mu \mathrm{m}$ and the combination of $2 \mathrm{~mm}+600 \mu \mathrm{m}$ are comparable. Comparison of the penetration depth measured in the acrylic glass and silica glass tubes shows slight differences of the absolute values for the same swelling times (Figures 4 and 5).

The suspensions made of $\mathrm{Ca}^{2+} 20 \%$ and $\mathrm{Na}^{+} 8 \%$ show high values of penetration depth within glass beads of $600 \mu \mathrm{m}$ and the combination of $2 \mathrm{~mm}+600 \mu \mathrm{m}$ (Figures 4 and 5). This area is too large for a $\mu$-CT scan of high quality. Therefore, the solid content of $\mathrm{Na}^{+}$ suspension was increased to $13 \%$ and the Ca $25 \%$ suspension was chosen for further testing. Following general observations can be made:

- The penetration depth in the glass beads decreases with increasing swelling time of the bentonite suspension. Here, $\mathrm{Ca}^{2+}$ bentonite shows a distinct response in terms if a reduced penetration depth in comparison to $\mathrm{Na}^{+}$bentonite.

- The general performance of the penetration behavior is irrespective of the material of the test tube within a swelling time up to 120 hours. Slight differences of absolute values of penetration depth are detected. Bentonite suspensions with swelling times beyond 120 hours should be refused for the $\mu$-CT scans.

- The penetration depth of the same bentonite suspension in glass beads of $600 \mu \mathrm{m}$ and the combination of $2 \mathrm{~mm}+600 \mu \mathrm{m}$ are equal. The penetration depth in glass beads of $2 \mathrm{~mm}$ is higher by trend. 
Solid Earth Discuss., doi:10.5194/se-2016-42, 2016

Manuscript under review for journal Solid Earth

Published: 8 March 2016

(c) Author(s) 2016. CC-BY 3.0 License.

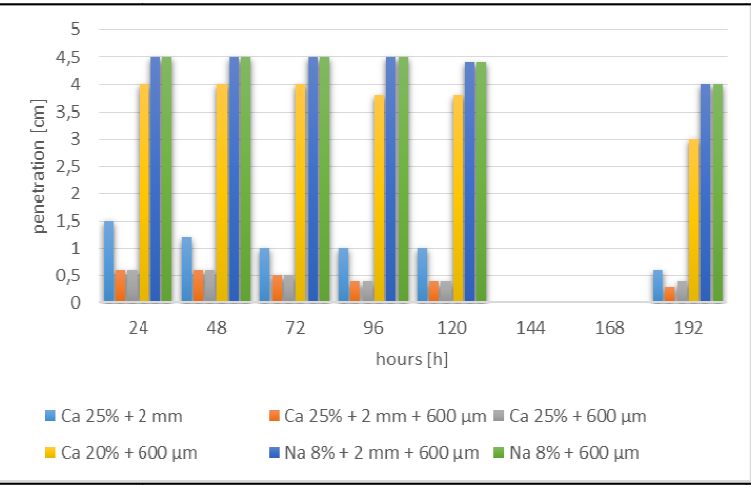

Figure 4: Development of penetration depth $(\mathrm{cm})$ of bentonite suspension in glass beads using test tubes made of acrylic glass for increasing swelling times $(\mathrm{h})$

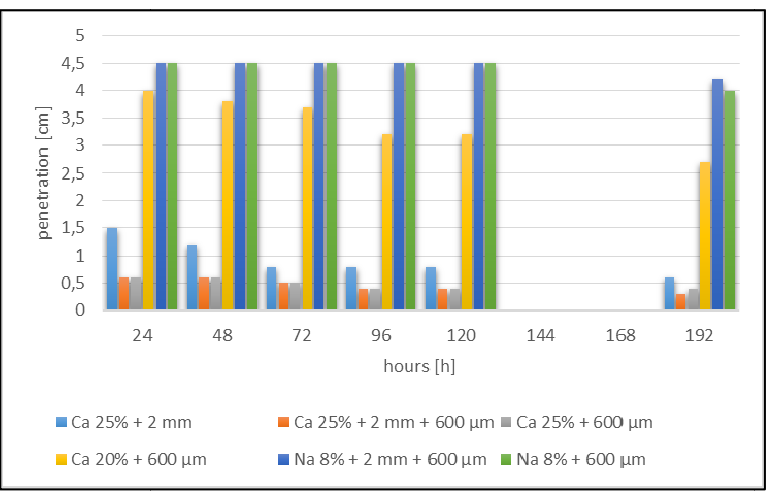

Figure 5: Development of penetration depth $(\mathrm{cm})$ of bentonite suspension in glass beads using test tubes made of quartz glass for increasing swelling times $(h)$

\section{$2.3 \quad \mu$-CT Imaging}

X-ray computed tomography was used for the $3 \mathrm{D}$ imaging of the samples, using a nanotom $\mathrm{S} 180 \mu$-CT (tube characteristics: $180 \mathrm{kV}, 500 \mathrm{~mA}$ ) device, of the Leibniz Institute for Applied Geophysics (Tab. 2). The nanotom is a compact CT system for pore scale imaging purposes, i.e. for high resolution imaging within the micrometer (typically 1-2 $\mu \mathrm{m}$ ) to sub-micrometer range (about $700 \mathrm{~nm}$ for very small samples), featuring high image sharpness due to a significantly reduced penumbra effect [Brunke et al. 2008]. A comprehensive overview of $\mu$ CT imaging and 3D image reconstruction is given by Buzug (2010). The 3D image data were processed with the AVIZO Fire software suite (Visualization Sciences Group). Due to the low image noise and due to the fact that only few phases exist for segmentation, phase segmentation processing has been performed by the fast and robust "automatic threshold selection method" described by Otsu (1979). 
Solid Earth Discuss., doi:10.5194/se-2016-42, 2016

Manuscript under review for journal Solid Earth

Published: 8 March 2016

(c) Author(s) 2016. CC-BY 3.0 License.

\section{$2.4 \quad$ Image Processing}

The preparation and execution of the $\mu$-CT scans followed a standardized procedure:

1. Sample preparation;

2. Sample installation and $\mu-C T$ setup;

3. $\mu-C T$ scan;

4. 3D data reconstruction;

5. Image processing and analysis.

Here, the glass beads are filled in the test tube using a funnel equipment with a specific height to provide a constant dense packing or density. Afterwards, the bentonite suspension was added and the penetration process took place. The time period for finishing this process is short $(<2 \mathrm{~min})$. The test tube is installed and the $\mu$-CT device, i.e. detector and tube setup, are prepared individually (Table 2). All samples have been positioned such way, that the interfacial surface area between the suspension - glass bead - air filled void space has been investigated as a region of interest. After data reconstruction, the $3 \mathrm{D}$ data sets have been processed with the AVIZO Fire software suite. Image processing has been performed for all samples as followed:

1. Data filtering (either using a median or a non local means filter [Ohser \& Schladitz, 2009]);

2. Phase segmentation (void space, suspension, matrix);

3. Pore space analysis (pore separation, pore size distribution, porosity);

4. Grain size analysis (grain separation, grain size distribution);

5. Suspension distribution analysis (spatial extent, air inclusions and contact angles).

Table 2: Parameters of detector and tube setup

\begin{tabular}{|c|c|c|c|c|c|c|}
\hline CT values & $2 \mathrm{~mm}$ & $\begin{array}{c}2 \\
\text { Ca } 25 \\
\text { silica gl } \\
600 \mu \mathrm{m}\end{array}$ & $2 \mathrm{~mm}+600 \mu \mathrm{m}$ & $\begin{array}{c}5 \\
\text { Ca } 25 \% \\
\text { acrylic glass } \\
2 \mathrm{~mm}\end{array}$ & $\begin{array}{c}4 \\
\text { Na } 8 \% \\
\text { silica glass } \\
600 \mu \mathrm{m}\end{array}$ & $\begin{array}{c}6 \\
\mathrm{Na} \mathbf{1 3 \%} \\
\text { silica glass } \\
2 \mathrm{~mm}+600 \mu \mathrm{m}\end{array}$ \\
\hline Voltage [kV] & 105 & 105 & 105 & 125 & 125 & 125 \\
\hline Current $[\mu \mathrm{A}]$ & 75 & 75 & 75 & 95 & 95 & 95 \\
\hline Timing [ms] & 750 & 750 & 750 & 750 & 750 & 750 \\
\hline Averaging [-] & 3 & 3 & 3 & 4 & 4 & 4 \\
\hline Skip [-] & 1 & 1 & 1 & 1 & 1 & 1 \\
\hline Image Number [-] & 1000 & 1000 & 1000 & 1200 & 1500 & 1500 \\
\hline
\end{tabular}

\section{$3 \quad$ Results}

\subsection{Porosity and pore size distribution of non-cohesive media}

The theoretical model of the penetration process of a bentonite suspension into noncohesive media depends - amongst others - on the porosity and permeability. In a soil mechanical sense, porosity is a dimensionless number that quantifies the existing pore space in reference to the whole soil volume. Here, the pores may be completely or partly filled with air, bentonite suspension or water. In addition, permeability is a measure for the 
Solid Earth Discuss., doi:10.5194/se-2016-42, 2016

Manuscript under review for journal Solid Earth

Published: 8 March 2016

(c) Author(s) 2016. CC-BY 3.0 License.

connectivity of the single pores. A high permeability is associated to a high porosity, but from a high porosity a high permeability cannot be deduced. A high porosity may be based on a huge amount of small pores or on the contrary on a small amount of big pores [Engelhard 1951]. In general, the porosity is determined by the shape, grading and compactness of the non-cohesive media / soil particles.

Basically, porosity is identical for samples with the same volume, particle shape, particle grading and compactness/density. For determination of porosity using $\mu$-CT imaging, three samples were chosen: Sample 1: silica glass - Ca $25 \%-2 \mathrm{~mm}$, Sample 2: silica glass - Ca $25 \%-600 \mu \mathrm{m}$, Sample 3: silica glass - Ca $25 \%-2 \mathrm{~mm}+60 \mu \mathrm{m}$ (Figure 6). The analyzed volume was identical; the non-local-means filter was applied. Table 3 presents information concerning the resulting porosity, pore size and quantity of pores.

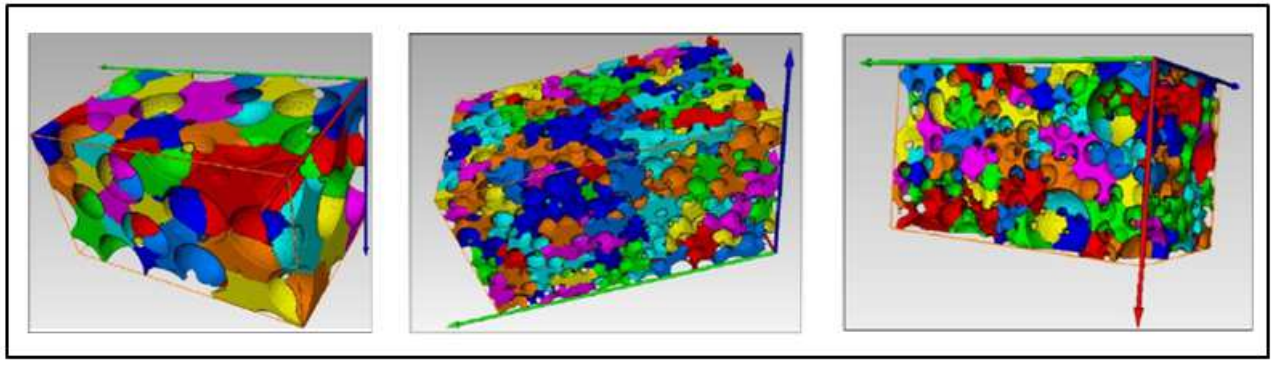

Figure 6: 3D-illustrations of pore space of glass beads of Sample 1 (2 mm - left), Sample 2 (600 $\mu \mathrm{m}-$ center) and Sample $3(2 \mathrm{~mm}+600 \mu \mathrm{m}-$ right $)$.

The porosity obtained from $\mu$-CT imaging fits well the experimental determined values. The latter were determined by comparison of the weight of materials under dry and watersaturated conditions. Here, distilled water with a density of $1000 \mathrm{~kg} / \mathrm{m}^{3}$ was used.

Table 3: Results of analyzing porosity and pore size of glass beads $2 \mathrm{~mm}, 600 \mu \mathrm{m}$ and combination 2 $\mathrm{mm}+600 \mu \mathrm{m}$

\begin{tabular}{|c|c|c|c|c|c|c|c|c|}
\hline \multirow[t]{2}{*}{ Sample } & \multirow{2}{*}{\begin{tabular}{|c|} 
Porosity \\
numerical
\end{tabular}} & \multicolumn{4}{|c|}{ Diameter of pore space $[\mathrm{mm}]$} & \multirow{2}{*}{$\begin{array}{l}\text { Quantity } \\
\text { of pores }\end{array}$} & \multirow{2}{*}{\begin{tabular}{|c|} 
Threshold \\
value
\end{tabular}} & \multirow{2}{*}{$\begin{array}{c}\text { Porosity } \\
\text { experimental }\end{array}$} \\
\hline & & Min. & Max. & Average & Median & & & \\
\hline 1: Silica glass Ca $25 \% 2 \mathrm{~mm}$ & $39.60 \%$ & 0.597 & 2.081 & 1.167 & 1.071 & 81 & 9703 & $41.40 \%$ \\
\hline 2: Silica glass Ca $25 \% 600 \mu \mathrm{m}$ & $39.28 \%$ & 0.377 & 1.369 & 0.746 & 0.726 & 355 & 7014 & $40.80 \%$ \\
\hline 3: Silica glass Ca $25 \% 2 m m+600 \mu m$ & $34.59 \%$ & 0.209 & 1.457 & 0.782 & 0.783 & 259 & 13701 & $34.08 \%$ \\
\hline
\end{tabular}

Comparing the porosity values in Table 3 shows evidence for the general laws of soil mechanics: glass beads with only one particle size of $2 \mathrm{~mm}$ or $600 \mu \mathrm{m}$ show nearly identical values of porosity of $39.60 \%(2 \mathrm{~mm})$ and $39.28 \%(600 \mu \mathrm{m})$ due to the same volume and the same bulk density. Thereby, the $2 \mathrm{~mm}$ glass beads provide a smaller quantity of pores due to a higher median value of the pore size diameter, while the $600 \mu \mathrm{m}$ glass beads provide a higher pore quantity due to smaller median value of the pore size diameter.

In contrast, the particle size of the glass beads of Sample 3 contains a ratio of $50 \% / 50 \%$ of $2 \mathrm{~mm} / 600 \mu \mathrm{m}$. Porosity is smaller due to the fact, that the smaller glass beads of $600 \mu \mathrm{m}$ fit into the pore space of the bigger glass beads of $2 \mathrm{~mm}$. Therefore, the porosity of this mixture reduces to $34.59 \%$. 
Solid Earth Discuss., doi:10.5194/se-2016-42, 2016

Manuscript under review for journal Solid Earth

Published: 8 March 2016

(c) Author(s) 2016. CC-BY 3.0 License.

The characterization of the pore space concerning pore size, porosity and thus permeability are evident for the analysis of the penetration behavior of the bentonite suspension. Therefore, the histograms of pore size distribution are transferred into a diagram showing the size of the pores in reference to the proportion of the pores for glass beads of $2 \mathrm{~mm}$ (Sample 1), $600 \mu \mathrm{m}$ (Sample 2) and combination of $2 \mathrm{~mm}+600 \mu \mathrm{m}$ (Sample 3) in Figure 7.

5

Figure 7: Pore size distribution of glass beads $2 \mathrm{~mm}$ (Sample 1), $600 \mu \mathrm{m}$ (Sample 2) and combination $2 \mathrm{~mm}+600 \mu \mathrm{m}$ (Sample 3).

\subsection{Segmentation of penetration depth and filter cake}

\subsubsection{Sample 1: Ca $25 \%$ - silica glass $-2 \mathrm{~mm}$}

Sample 1 contains a viscous bentonite suspension $\mathrm{Ca} 25 \%$. The penetration depth was determined optically and by using imaging with application of module "Measurement". Due to an even penetration performance, both results show the same value of $15 \mathrm{~mm}$ penetration depth of the suspension into the pore space of the $2 \mathrm{~mm}$ glass beads packing (Figure 8). The visualization of the sample shows artefacts below the penetration zone in the area of dry glass beads. From the optical point of view an explicit boundary exist between the pore space filled with bentonite suspension and the air filled pores. Due to the coarse material the penetration effect took place. Following the visualization and analysis of the $3 \mathrm{D}$ data, it can be demonstrated that the suspension flows as a homogenous fluid into the pores and stagnates at the depth of $15 \mathrm{~mm}$. 
Solid Earth Discuss., doi:10.5194/se-2016-42, 2016

Manuscript under review for journal Solid Earth

Published: 8 March 2016

(c) Author(s) 2016. CC-BY 3.0 License.

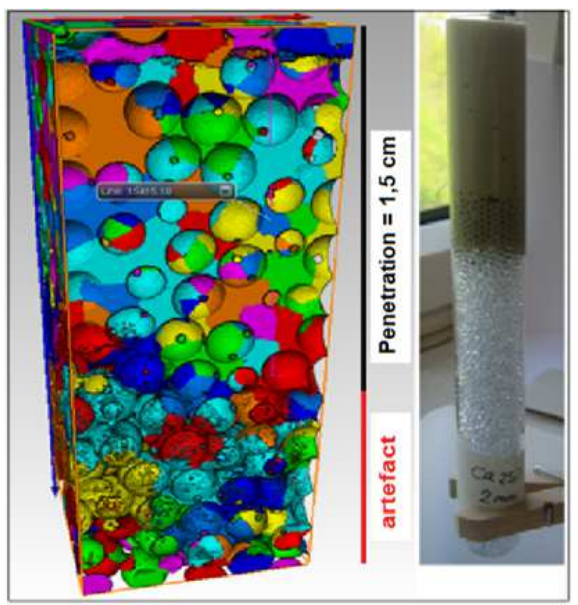

Figure 8: Sample 1, 3D embodiment of penetration depth.

This effect was revised by investigating the three-phase situation in a histogram (Figure 9). This Histogram represents a vertical line through the sample and shows different grey values of the detected media. Here, the glass beads have the highest density and therefore show the highest grey value. The lower the density of the medium, the lower the grey value in the histogram. Analyzing the grey value using the module "Line Probe" shows three different values of glass beads, bentonite suspension and air within the pore space (Figure 9). The suspension is identified at nearly the same representative values. This feature indicates that the concentration/solid content of the suspension remains constant within the pore space, the suspension stays as a homogenous fluid within the pores.

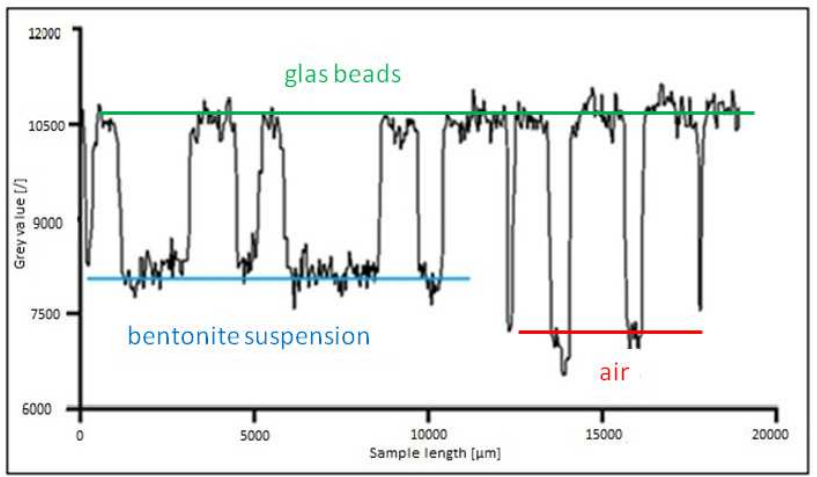

Figure 9: Sample 1: Identification of three phases: glass beads, bentonite suspension and air.

\subsubsection{Sample 2: Ca $25 \%$ - silica glass - $600 \mu \mathrm{m}$}

Sample 2 contains the same viscous bentonite suspension as Sample 1. Due to an uneven penetration process, the visible penetration depth of $5 \mathrm{~mm}(0.5 \mathrm{~cm})$ is smaller than the penetration depth determined by applying the module "measurement" using imaging of $9 \mathrm{~mm}$ $(0.9 \mathrm{~cm})$. Furthermore, the suspension penetrates deeper in the middle of the test tube into 
Solid Earth Discuss., doi:10.5194/se-2016-42, 2016

Manuscript under review for journal Solid Earth

Published: 8 March 2016

(c) Author(s) 2016. CC-BY 3.0 License.

the pore space than at the visible edge (Figure 10, left). The small glass beads tend to be buoyant in the viscous fluid. Despite that, the bentonite suspension penetrates as a homogeneous fluid into the glass beads. Again, an explicit boundary exists between the pore space filled with bentonite suspension and the air filled pores.

Analyzing the grey value using the module "Line Probe" shows again three different values of glass beads, air and bentonite suspension within the pore space (Figure 10, right). The suspension remains at nearly the same representative value that means the concentration or solid content of the suspension is constant within the pore space (three phases).

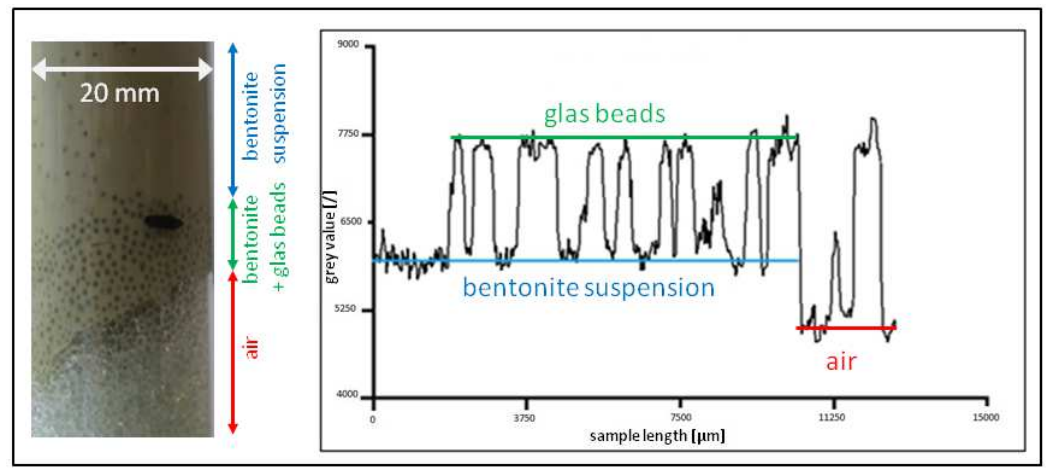

Figure 10: Sample 2, Identification of three phases: glass beads, bentonite suspension and air.

\subsubsection{Sample 3: Ca $25 \%$ - silica glass $-2 \mathrm{~mm}+600 \mu \mathrm{m}$}

Sample 3 shows the penetration process of viscous bentonite suspension $\mathrm{Ca} 25 \%$ into the combination of $2 \mathrm{~mm}+600 \mu \mathrm{m}$. The uneven penetration process leads to the deviation of the visible penetration depth of $8 \mathrm{~mm}(0.8 \mathrm{~cm})$ in comparison to the penetration depth determined by applying the module "measurement" between $6 \mathrm{~mm}(0.6 \mathrm{~cm})$ and $8 \mathrm{~mm}(0.8$ $\mathrm{cm})$. The mean value of the penetration depth is comparable to the value of Sample 2 with glass beads of $600 \mu \mathrm{m}$. The visualization of the sample shows artifacts below the penetration zone in the area of dry glass beads (Figure 11, left). Some of the small glass beads tend to be buoyant too in the viscous fluid. In general, the bentonite suspension penetrates as a homogeneous fluid into the pore space of the glass beads. Again, an explicit boundary exists between the pore space filled with bentonite suspension and the air filled pores.

Analyzing the grey value using the module "Line Probe" shows again three different values of glass beads, air and bentonite suspension within the pore space (Figure 11, right). The suspension remains at nearly the same representative value that means the concentration or solid content of the suspension is constant within the pore space (three phases). 
Solid Earth Discuss., doi:10.5194/se-2016-42, 2016

Manuscript under review for journal Solid Earth

Published: 8 March 2016

(c) Author(s) 2016. CC-BY 3.0 License.

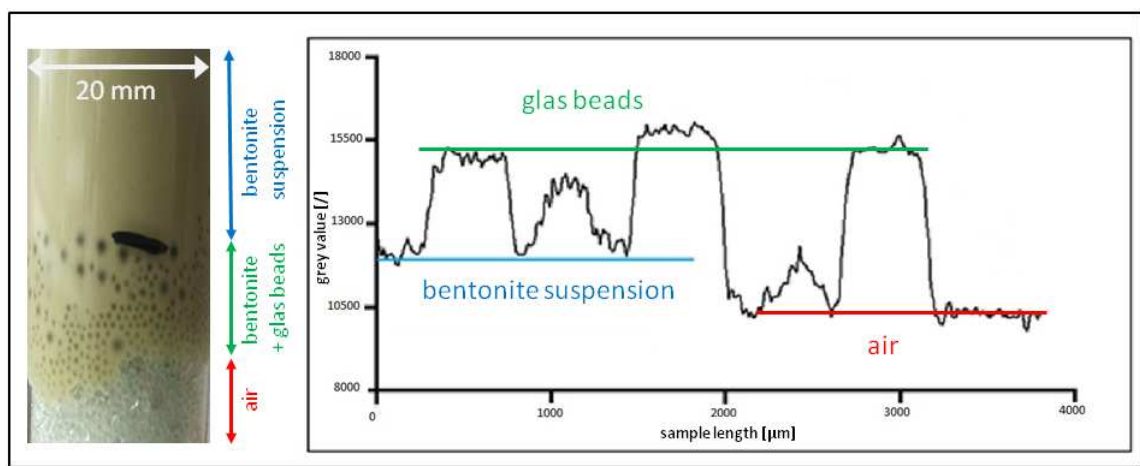

Figure 11: Sample 3: Identification of 3 phases: glass beads, bentonite suspension and air.

\subsubsection{Sample 4: Na $8 \%$ - silica glass $-600 \mu \mathrm{m}$}

In Sample 4 the Na $8 \%$ suspension penetrates into glass beads $600 \mu \mathrm{m}$ and results in a penetration depth of $23 \mathrm{~mm}$ (Figure 12, left). This value is quite high in comparison to the penetration depth of $5 \mathrm{~mm}(0.5 \mathrm{~cm})$ of $\mathrm{Ca} 25 \%$ in Sample 2 in the $600 \mu \mathrm{m}$ glass beads. On the one hand, the $\mathrm{Ca} 25 \%$ suspension is the more viscous fluid due to the higher solid content. On the other hand, the determination of the bentonite particle size (Appendix 1) shows a mean value of $10 \mu \mathrm{m}$ for $\mathrm{Ca}$-particles and of $7 \mu \mathrm{m}$ for Na-particles. Therefore, the $\mathrm{Na}$ bentonite suspensions are predestined to move deeper into a pore space of the same size than the $\mathrm{Ca}$ bentonite suspension. Furthermore, in Figure 12 (left) it is visible that a certain amount of water filters out of the bentonite suspension.

This phenomenon can be validated by analyzing the grey value using the module "Line Probe". Here, four different values for glass beads, air, bentonite suspension and water are identified on the vertical sketch (Figure 12, right). The amount of water is very low and concentrates on a very limited area within the test tube. As it can be seen from Figure 12, the water flows at the inner tube walls. The histogram in Figure 12 shows a nearly constant value of the bentonite suspension. It appears that the concentration/solid content of the suspension does not change significantly within the pore space.

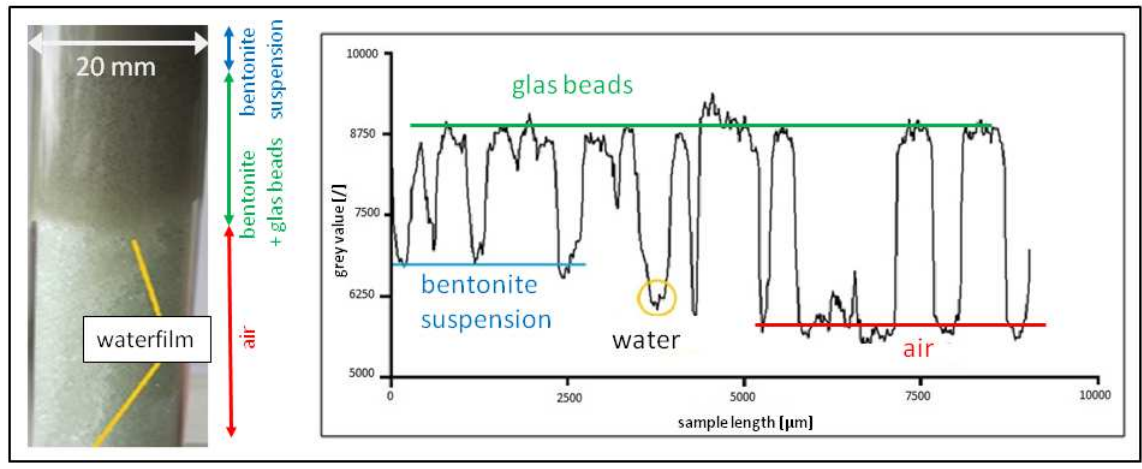

Figure 12: Sample 4, identification of four phases: glass beads, bentonite suspension, water and air. 
Solid Earth Discuss., doi:10.5194/se-2016-42, 2016

Manuscript under review for journal Solid Earth

Published: 8 March 2016

(c) Author(s) 2016. CC-BY 3.0 License.

\subsubsection{Sample 5: Ca $25 \%$ - acrylic glass - $2 \mathrm{~mm}$}

Sample 5 shows the penetration process of viscous bentonite suspension Ca $25 \%$ into 2 $\mathrm{mm}$ glass beads whereas the test tube is made of acrylic glass. The even penetration process leads to the visible penetration depth of $15 \mathrm{~mm}(1.5 \mathrm{~cm})$ and to the penetration depth of $15 \mathrm{~mm}(1.5 \mathrm{~cm})$ determined by applying the module "Measurement" (Figure 13). This value matches the penetration depth of Sample 1 using $\mathrm{Ca} 25 \%$ and glass beads of 2 $\mathrm{mm}$ in a test tube made of silica glass (Figure 8). It provides evidence that the material of the test tube has no influence on the penetration depth.

The visualization of Sample 5 shows artifacts below the penetration zone in the area of dry glass beads (Figure 13). Some of the small glass beads tend to be buoyant too in the viscous fluid. In general, the bentonite suspension penetrates as a homogeneous fluid into the pore space of the glass beads. Again, an explicit boundary exists between the pore space filled with bentonite suspension and the air filled pores.

The analysis of the grey value using the module "Line Probe" shows an additional phase of water below the end of the penetration zone of the suspension within the pore space (Figure 13). The water does not appear at the walls of the test tubes, it is located inside the glass beads.

The $\mu$-CT scanning is based on the detection of media with different densities. The larger the difference in density, the easier the single media can be identified. However, the density value of water $1000 \mathrm{~kg} / \mathrm{m}^{3}$ is close to the density of the Ca $25 \%$ suspension $1025 \mathrm{~kg} / \mathrm{m}^{3}$. The left side of the histogram (Figure 13) shows the grey value of the bentonite suspension that is placed above the area of glass beads (sample length approx. $0-2500 \mu \mathrm{m}$ ). Within the pore space of the glass beads (sample length approx. $5000-16000 \mu \mathrm{m}$ ), the grey value of the bentonite suspension is slightly higher. In addition, the filtrated water shows a lower grey value close to the original bentonite suspension. This gives evidence that a filter process took place within the pore space. Here, the suspension water is separated in a small amount from the bentonite particles. The particles remain in the pore space, the filtrate water drains into the pore space below. The solid content/density of the bentonite suspension within the pores increases gently, in place where some suspension water is filtrated.

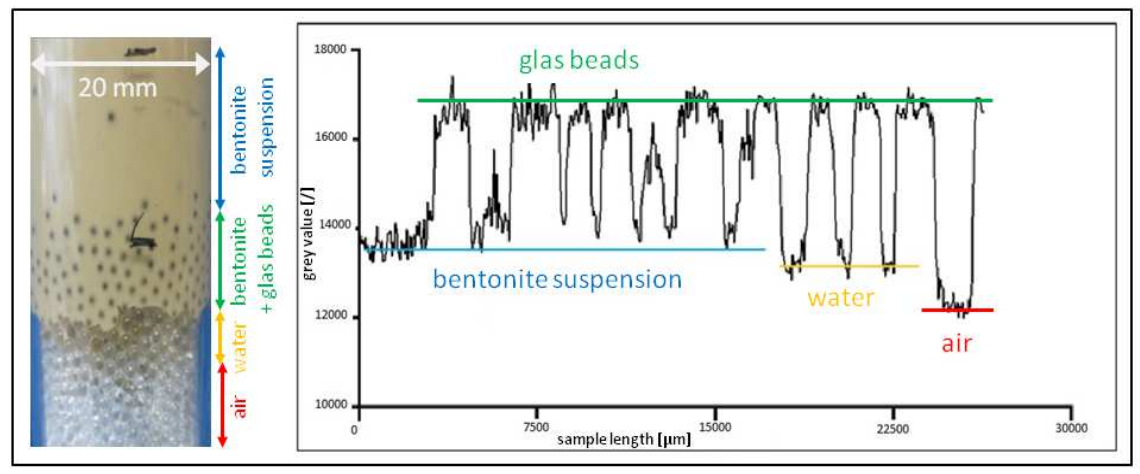

Figure 13: Sample 5, identification of four phases: glass beads, bentonite suspension, water and air using Histogram. 
Solid Earth Discuss., doi:10.5194/se-2016-42, 2016

Manuscript under review for journal Solid Earth

Published: 8 March 2016

(c) Author(s) 2016. CC-BY 3.0 License.

\subsubsection{Sample 6: Na 13\% - silica glass $-2 \mathrm{~mm}+600 \mu \mathrm{m}$}

In Sample 6 the penetration process of bentonite suspension $\mathrm{Na} \mathrm{13 \%}$ performs into the combination of $2 \mathrm{~mm}+600 \mu \mathrm{m}$ glass beads in a test tube of silica glass. Here, the infiltration leads to a filter cake performance at the entrance of the pore space of glass beads. The bentonite particles are filtered from the suspension, the bentonite particles attach gradually at the pore access and the filtrate water of the suspension drains through the glass beads (Figure 14). Therefore, the visualization of Sample 6 shows no penetration depth within the analysis using the module "measurement".

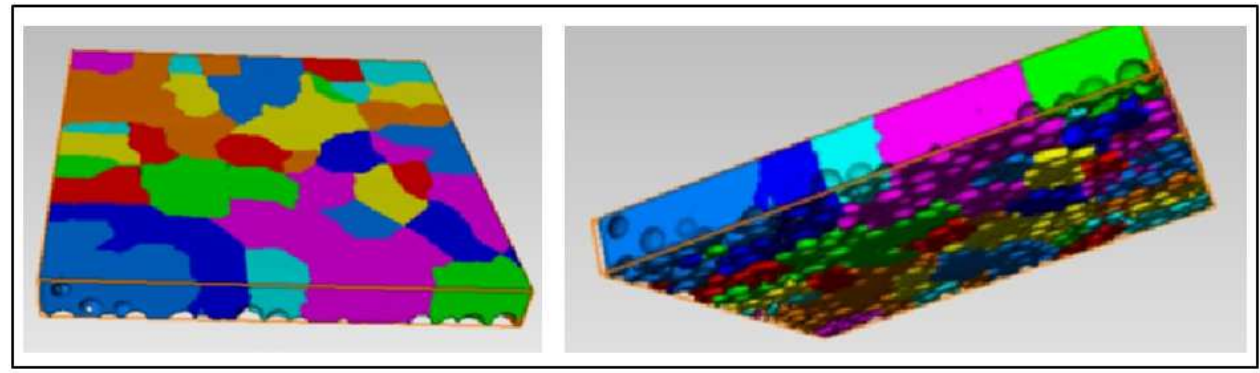

Figure 14: Sample 6: 3D embodiment of the area of filter cake as an assembly of solid material with a closed surface (left) and apparent accumulation of bentonite particles at the pore access (right).

The Histogram in Figure 15 shows the increase of the density of the bentonite suspension within a short area/depth followed by the detection of the filtrate water. The grey value of the bentonite suspension above the level of glass beads is shown. Within the pore space of the glass beads the grey value of the bentonite suspension is slightly higher than the filtrate water shows a lower grey value. This gives evidence that the filtration process of the bentonite particles took place at the pore access. The suspension water is separated from the bentonite particles. The particles remain in the pore space, the filtrate water drains into the pore space below. The solid content/density of the bentonite suspension within the pores increases, which is verified by increasing grey values.

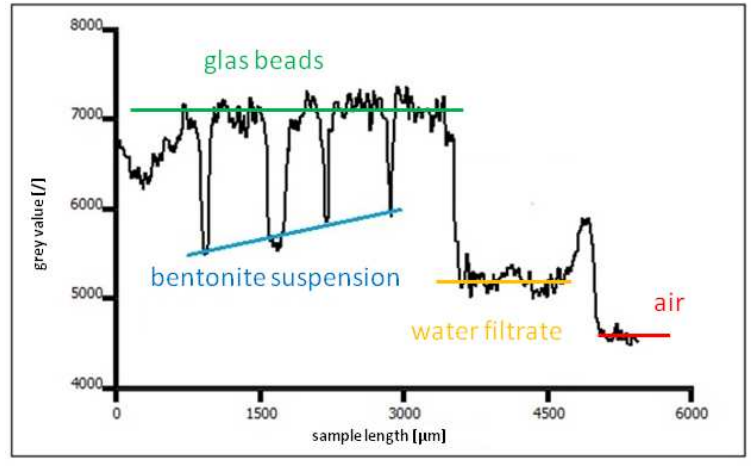

Figure 15: Sample 6, identification of four phases: glass beads, bentonite, filtrate water and air, especially the density of the bentonite suspension varies. 
Solid Earth Discuss., doi:10.5194/se-2016-42, 2016

Manuscript under review for journal Solid Earth

Published: 8 March 2016

(c) Author(s) 2016. CC-BY 3.0 License.

\subsection{Contact angle of bentonite suspensions and glass beads}

In general, the contact angle determined using $\mu$-CT imaging helps to classify the manner of interaction between a fluid and the surface of a solid, e.g. type of fluid, material and surface roughness of solid. A contact angle of $90^{\circ}$ is the limit between a wetting and non-wetting fluid. Contact angles over are typical for Mercury, contact angles less than $90^{\circ}$ present the behavior of Water (Figure 16).

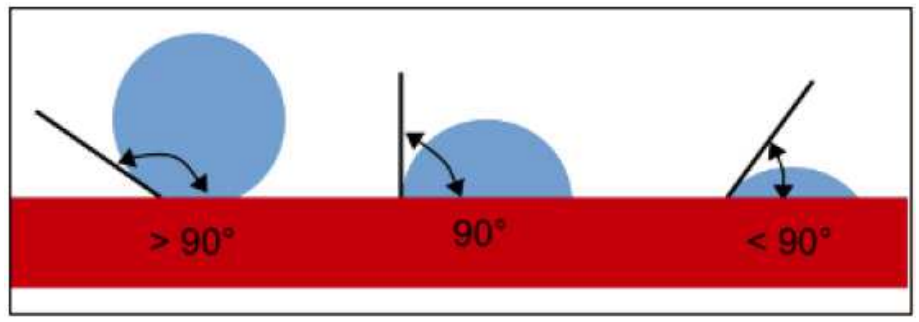

Figure 16: General classification of a non-wetting fluid (contact angle $>90^{\circ}$, left), partial wetting fluid (contact angle $=90^{\circ}$, center) and completely wetting fluid (contact angle $<90^{\circ}$, right).

For the bentonite suspension Ca $25 \%$ the contact angles are determined using the module "angular measurement" for the different glass beads $2 \mathrm{~mm}$ (Sample 1), $600 \mu \mathrm{m}$ (Sample 2) and $2 \mathrm{~mm}+600 \mu \mathrm{m}$ (Sample 3). Table 4 shows the results of contact angles. In general, the contact angle for bentonite suspension $\mathrm{Ca} 25 \%$ is smaller than $90^{\circ}$. The suspension is classified as a wetting fluid.

Table 4: Results of determination of contact angles between bentonite suspension and glass beads in Sample $1 \mathrm{Ca} 25 \% 2 \mathrm{~mm}$, Sample $2 \mathrm{Ca} 25 \% 600 \mu \mathrm{m}$ and Sample $3 \mathrm{Ca} 25 \% 2 \mathrm{~mm}+600 \mu \mathrm{m}$ in test tubes of silica glass. 
Solid Earth Discuss., doi:10.5194/se-2016-42, 2016

Manuscript under review for journal Solid Earth

Published: 8 March 2016

(c) Author(s) 2016. CC-BY 3.0 License.

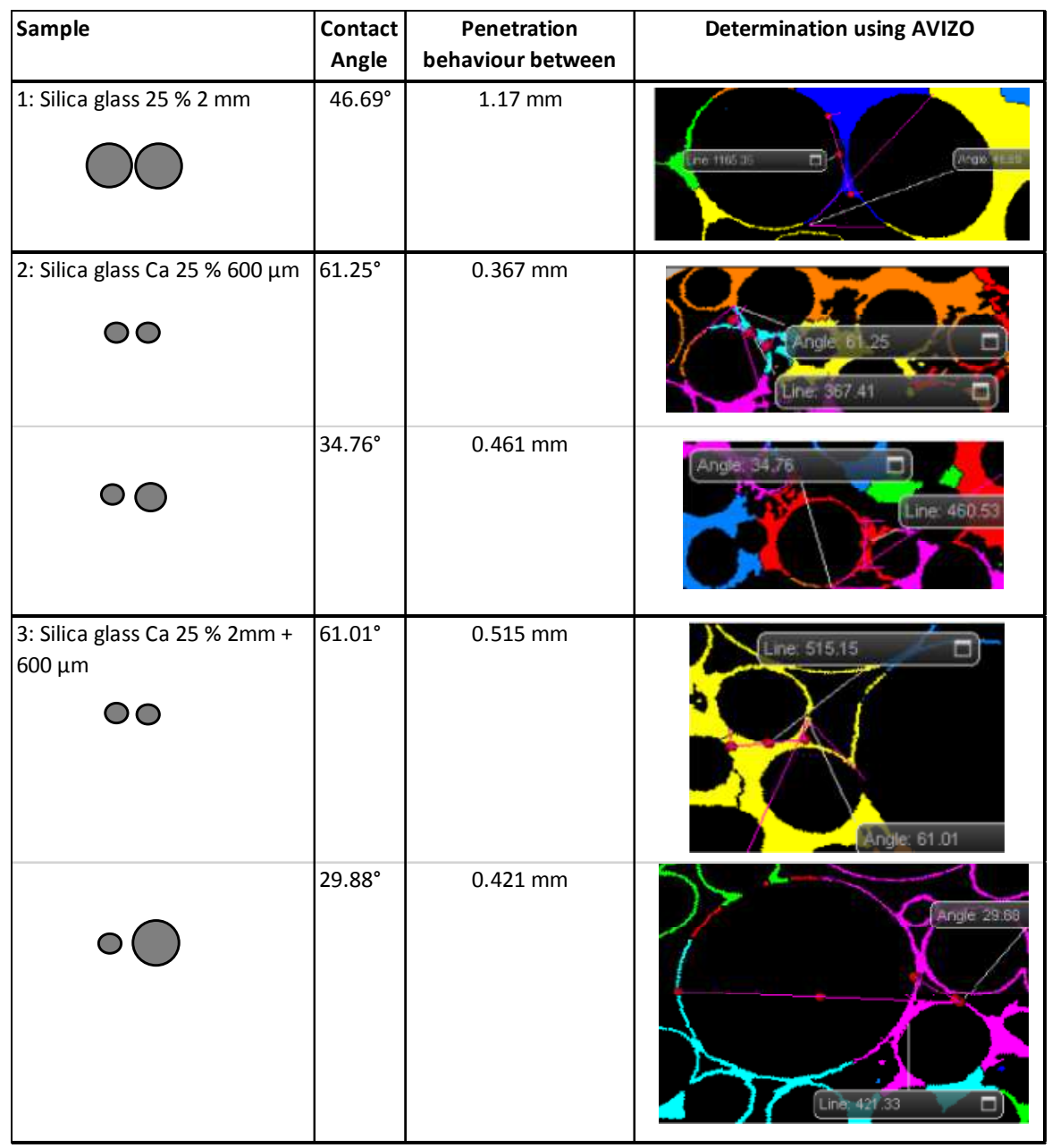

\section{Discussion}

In this study, two different bentonites $\mathrm{Ca}^{2+}$ and $\mathrm{Na}^{+}$were used. Samples $1,2,3$ and 5 contain Ca-bentonite with solid content of $25 \%$. In Sample 1 and 5 the bentonite suspension penetrates into glass beads $2 \mathrm{~mm}$ and both tests perform identical values for penetration depth of $15 \mathrm{~mm}$. It can be shown, that the material of the test tube - silica glass or acrylic glass - does not influence the result of the penetration test (Figure 8 and 12).

Using the smaller glass beads of $600 \mu \mathrm{m}$ and the combination of $2 \mathrm{~mm}+600 \mu \mathrm{m}$, the penetration depth reduces considerably (Figure 10 and 11). As shown in Figure 7, the distribution of the pore size is nearly identical for glass beads of $600 \mu \mathrm{m}$ and the combination of $2 \mathrm{~mm}+600 \mu \mathrm{m}$. In general, the pore size ranges between $0.3 \mathrm{~mm}-1.5 \mathrm{~mm}$ with a peak around $0.7 \mathrm{~mm}$. The range of pore size for the $2 \mathrm{~mm}$ glass beads is between $0.6 \mathrm{~mm}-2.1$ $\mathrm{mm}$ with a peak around $0.9 \mathrm{~mm}$. As a consequence, the same bentonite suspension Ca 25 $\%$ with a particle size of approximately $10 \mu \mathrm{m}$ (Appendix 1) penetrates deeper into the glass beads $2 \mathrm{~mm}$ with larger pore size (Figure 17). 
Solid Earth Discuss., doi:10.5194/se-2016-42, 2016

Manuscript under review for journal Solid Earth

Published: 8 March 2016

(c) Author(s) 2016. CC-BY 3.0 License.

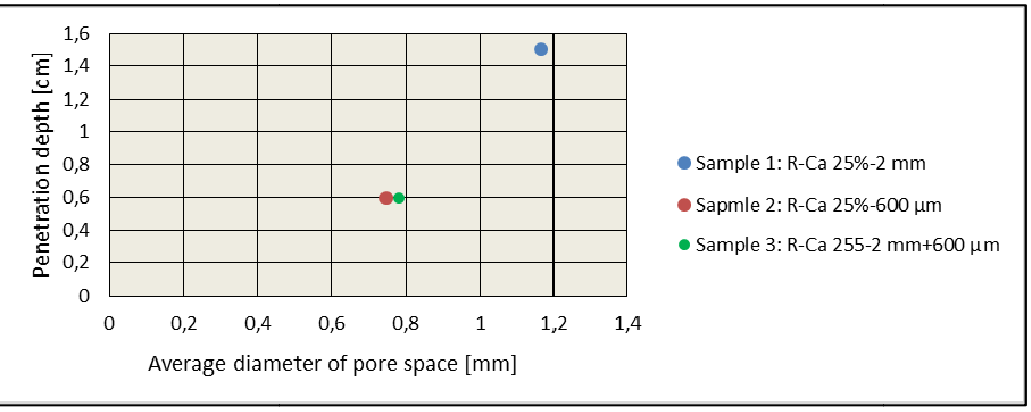

Figure 17: Average diameter of pore space [mm] within glass beads $2 \mathrm{~mm}, 600 \mu \mathrm{m}$ and combination $2 \mathrm{~mm}+600 \mu \mathrm{m}$ in reference to the determined penetration depth [cm].

The Histogram of Samples 1, 2, and 3 identifies three different phases: glass beads, bentonite suspension and air within the pore space. Here, the bentonite suspension penetrates as a homogeneous fluid into the pores of the coarse material. Within this study, this is defined as the "standard penetration behavior" and can be linked directly to the experimentally performed penetration zones in Figure 2 (right) on the macroscale. For the first time, this penetration behavior of bentonite suspension into coarse material is visualized on microscale using $\mu$-CT.

According to Appendix 1, Na-bentonites show a size of approximately $3 \mu \mathrm{m}$. Therefore, the penetration depth of $\mathrm{Na} 8 \%$ into glass beads of $600 \mu \mathrm{m}$ in Sample 4 reaches the largest value of the conducted test series $23 \mathrm{~mm}$ (see also Figure 5 and Figure 6). The larger the particles of Ca-bentonite (approximately $10 \mu \mathrm{m}$ ) the smaller the penetration depth into the same size of glass beads of Sample 2 and Sample 3.

Exceptionally, four different phases are detected within the histogram of Sample 4: glass beads, bentonite suspension, air and filtrated water at the lower area of the penetration depth. In addition, the histogram of Sample 5 identifies the same phases: glass beads, bentonite suspension, air and filtrated water. Compared to Sample 5, the area of filtrated water within Sample 4 is quite large. This may be due to the lower solid content of $\mathrm{Na} 8 \%$ (Sample 4) compared to Ca $25 \%$ (Sample 5).

Sample 6 using Na $13 \%$ and glass beads of combination $2 \mathrm{~mm}+600 \mu \mathrm{m}$ performs uniquely the filter cake within this test series. The bentonite particles remain at the "entrance" of the pore space of the glass beads and the filtrated suspension water flows deeper into the tube. The filter cake is illustrated in the 3D embodiment of Figure 14. Furthermore, the Histogram shows a varying density of the bentonite suspension within the limited filtration area at the pore space "entrance". For the first time, the performance of a filter cake of bentonite suspension is visualized on microscale using $\mu-C T$.

From the gained results of the six samples, a general classification concerning the performance of a penetration zone and of a filter cake cannot be derived. Furthermore, the reasons of the filtration of water within the penetration effect as seen in Sample 4 and 5 using different types of bentonite cannot be explained satisfyingly. Here, further research work is needed. 
Solid Earth Discuss., doi:10.5194/se-2016-42, 2016

Manuscript under review for journal Solid Earth

Published: 8 March 2016

(c) Author(s) 2016. CC-BY 3.0 License.

\section{Conclusions}

The aim of this study is the visualization and analysis of the penetration behavior of bentonite suspensions in non-cohesive granular material on microscale using $\mu$-CT scanning.

The widely accepted scenarios of filter cake formation and entire penetration of the suspension into the pore space were conducted experimentally in test tubes using different combinations of bentonite suspension and granular material (glass beads). These phenomena were scanned with high-resolution $\mu-\mathrm{CT}$ technique. The 3D embodiment of the different samples were analyzed concerning soil mechanical aspects, e.g. particle size distribution, pore size distribution, porosity of the granular material, and concerning the interaction of the bentonite suspension within the pore space, e.g. contact angle, penetration depth and filter cake thickness.

These effects are verified by investigating the different phase situation in a histogram. The Histogram represents a vertical line through the sample and shows different grey values of the detected media. The lower the density of the medium, the lower the grey value in the histogram. Here, the histogram of each sample offers the identification of single phases: glass beads, bentonite suspension and air as well as the filter cake at the "entrance" of the pore space of the glass beads or the variation of density of a bentonite suspension filtrating within the penetration depth.

Sample 1, 2 and 3 show the penetration behavior of bentonite suspension into coarse material is visualized on microscale using $\mu$-CT. Three phases - glass beads, bentonite suspension and air - are detected in the Histogram. An additional phase - water filtrated from the suspension - is identified in Sample 4 and 5. The performance of a filter cake of bentonite suspension is visualized in Sample 6 on microscale using $\mu-C T$. The agglomeration of the bentonite particles at the entrance of the pore space results in the development of a filter cake. This area is identified as a distinct media. Furthermore, the histogram of Sample 6 shows a varying density of the bentonite suspension within the limited filtration area at the pore space "entrance".

In summary, the $\mu-C T$ technique delivers a valuable contribution for the research on the interaction of bentonite suspensions penetration the pore space of non-cohesive media. This study shows the missing visual evidence concerning the theoretical interaction models of the bentonite suspension in the pore space on microscale.

\section{Acknowledgements}

The authors wish to thank the German Research Foundation (DFG) for the financial support of this work within the framework of the subproject A6 "Local transient face support in hydro shield tunneling" of Collaborative Research Center SFB 837 "Interaction models in mechanized tunneling." The SEM image of glass beads was obtained by Dr. A. Roettger and J. Knuepferle from Ruhr-University Bochum. We thank for their contribution. We would also like to thank the reviewers for their constructive comments, which helped to improve this paper. 
Solid Earth Discuss., doi:10.5194/se-2016-42, 2016

Manuscript under review for journal Solid Earth

Published: 8 March 2016

(c) Author(s) 2016. CC-BY 3.0 License.

\section{References}

Anagnostou, G., Kovári, K. (1994), The Face stability in Slurry-shield-driven Tunnels. Tunnelling and Underground Space Technology No. 2 1994, pp. 165-174.

API RP 13B American Standard API 13B-1, 2009. Recommended Practice for Field Testing of Water-based Drilling Fluids. 4th edition, American Petroleum Institute

Arwanitaki, A. (2009): Über das Kontaktverhalten zwischen einer Zweiphasenschlitzwand und dem anstehenden Boden. PhD Thesis, Ruhr-Universitaet Bochum, Faculty of Civil Engineering.

Bezuijen A., Pruiksma J. P., van Meerten H. H. (2001): Pore pressures in front of tunnel, measurements, calculations and consequences for stability of tunnel face, In Adachi, T., K. Tateyama \& M. Kimura (eds), Modern Tunneling Science and Technology, pp. 799-804. Rotterdam, Balkema.

Boere, W. (2001): Tunnel face stability and new CPT applications, PhD thesis, Delft University.

Brunke, O., Brockdorf, K., Drews, S., Müller, B., Donath, T., Herzen, J., Beckmann, F. (2008): Comparison between X-ray tube based and synchrotron radiation based micro CT. In: Proceedings Development in X-Ray Tomography VI, Vol. 7078, International Society of Optics and Photonics.

Buzug, T. (2010): Computed Tomography - From Photon Statistics to Modern Cone-Beam CT, 522 pp., Springer, Berlin. Doi 10.1007/978-3-540-39408-2

DIN 4126:2013-09: Nachweis der Standsicherheit von Schlitzwänden (Stability analysis of diaphragm walls), 2013 (in German).

Engelhardt, H. (1951): Über die Zusammenhänge zwischen Porosität, Permeabilität und Korngröße bei Sanden und Sandsteinen. Heidelberger Beiträge zur Mineralogie und Petrographie, (2) pp. 477-491.

Heinz, A. (2006): Modifizierte Bentonitsuspensionen für geotechnische Bauverfahren in Böden hoher Durchlässigkeit (modifued bentonite suspension for geotechnical construction methods in high permeable soils, in German). PhD Thesis, Swiss Federal Institute of Technology, ETH Zurich, Switzerland.

Imerys Civil Engineering (1998): IBECO-Handbuch Bentonit im Tiefbau (1998) der Imerys Metalcasting Germany $\mathrm{GmbH}$. 
Solid Earth Discuss., doi:10.5194/se-2016-42, 2016

Manuscript under review for journal Solid Earth

Published: 8 March 2016

(c) Author(s) 2016. CC-BY 3.0 License.

586

Luckham, P.F., Rossi, S. (1999). The colloidal and rheological properties of bentonite suspensions, Advances in Colloid and Interface Science 8, pp 43-92

Maxey, J. (2007): Thixotropy and Yield Stress Behavior in Drilling Fluids, American Society of Drilling Engineers, AADE-07-NTCE-37

Min, F.; Zhu, W.; Han, X. (2013): Filter cake formation for slurry shield tunneling in highly permeable sand. Tunnelling and Underground Space Technology 38, pp 423-430

Mueller-Kirchenbauer, H. (1977): Stability of slurry trenches in inhomogeneous subsoil. Proceedings of 9th International Conference on Soil Mechanics and Foundation Engineering, Vol. 2, Tokyo.

Ohser, J. and Schladitz, K. (2009): 3D Images of Material Structures - Processing and Analysis, Wiley-VCH Publishing, Weinheim, Germany, 325 pp.

Otsu, N. (1979): A Threshold Selection Method from Gray-Level Histograms. IEEE Transact. Systems, Man, and Cybernetics, Vol. SMC-9, 1:62-66.

Krause, T. (1987): Schildvortrieb mit flüssigkeits- und erdgestützter Ortsbrust. PhD thesis, Technische Universität Carolo-Wilhelmina, Braunschweig.

Walz, B. (1989): Grundlagen der Flüssigkeitsstützung von Erdwänden. In: Tagungsband 10, Christian-Veder-Kolloquium, Graz.

Zizka Z., Thewes M. (2015): Face Support Pressure Calculations in shield Tunnelling, Draft prepared for DAUB and ITA-WG2.

\section{Appendix}
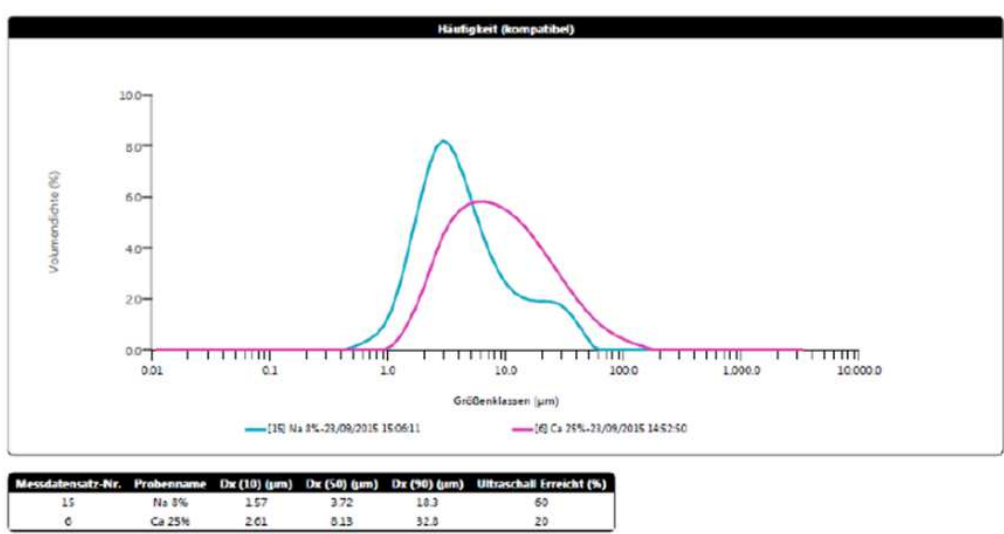

Appendix 1: Distribution of particle size $(\mu \mathrm{m})$ of $\mathrm{Na}^{+}$(blue line) and $\mathrm{Ca}^{2+}$ bentonite particles within the suspension (red line) in reference to quantity (\%) 